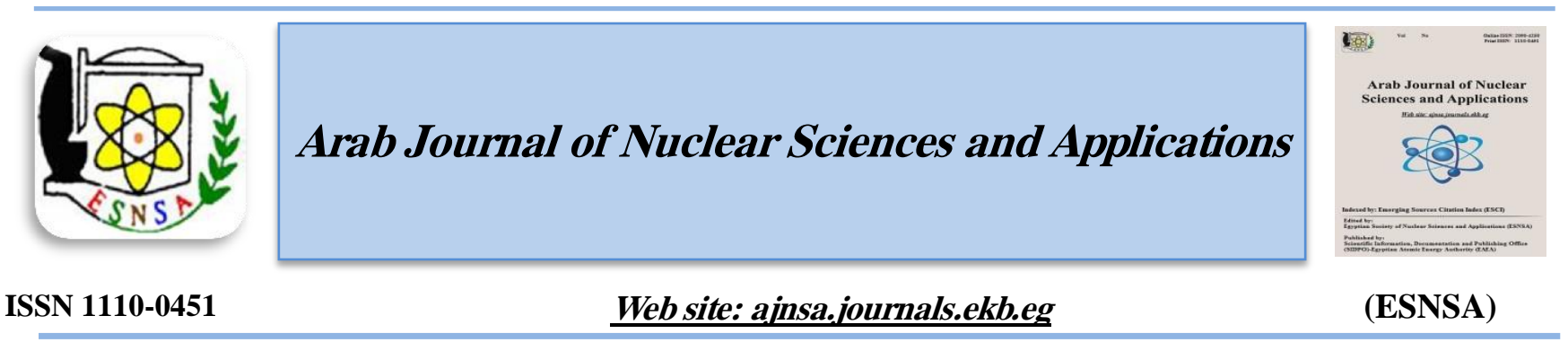

\title{
Relative Biophysical Effects on Rat's Bone as a Result of High Energy Photons and Electromagnetic Fields Exposures
}

\author{
Alaa M. Khalil \\ Basic Sciences Department, Faculty of Engineering, Pharos University in Alexandria, Egypt
}

Received $27^{\text {th }}$ Jun. 2018 There is critical need to do a lot of experimental studies to calculate of the relative biological effects of Accepted $24^{\text {th }}$ Apr. 2019 non-ionizing radiation and comparing its effect with ionizing radiation to re-determine the safe exposure dose to non-ionizing radiation. This research is concerned with studying the relative fraction of damage (RFD) of the extremely low frequency electromagnetic fields $(4 \mathrm{kV} / \mathrm{m}-50 \mathrm{~Hz})$ to high energy photons $(6$ $\mathrm{MeV}$ ) on some biophysical properties of rats bone. In this regard, 100 male albino rats are used and divided into sub groups of 10 rats each. One group of animals was used as control group (unexposed group) and did not receive any treatment. Similar to occupational workers, four groups of animals were exposed 8h/day for periods from 1 to 4 weeks and were immediately sacrificed at the end of the exposure period. Four groups of animals exposed 8h/day for periods from 1 to 4 weeks and remained 45 days post exposure periods, then sacrificed. The last group of animals was exposed to a high energy dose of6 MeV of dose (1 rad). Femur bone samples of each animal from all groups were collected and prepared for further biophysical investigations. In addition, RFD of magnetic fields exposures are calculated for each group relative to dose of $6 \mathrm{MeV}-1$ rad photons. Results of exposure to the electric field showed significant deterioration effect on the biomechanical parameters of femurs as a consequential defect of bone strength and bone quality as compared to the unexposed ones. Also, the results obtained from the groups that udergone a post exposure period of 45-days did not show amendment in bone biophysical characteristics, which means that permanent effects and chronic damage of bone tissues may have resulted. On the other hand, the RFD ratios illustrated that the effect of exposure to ELF EMF has no lower effect than the exposure to ionizing radiation and should not be underestimated.

Keywords: Electric field, Biomechanical, Biochemical, Femur, Bending moment

\section{Introduction}

In the modern society, greater use of technologies leads to increasing exposure to extremely lowfrequency electromagnetic fields (ELF-EMFs) generated by structures and appliances such as power lines and ordinary devices used inside house and work places. As a result, the effects of ELFEMFs on the human health represent an emerging area of interest with respect to environmental influences. Recently; several studies have been performed to verify direct effects exerted by ELF-
EMFs on living cells functions. Although the results have been somewhat controversial, a variety of cell responses have been observed involving proliferation and differentiation [1-3], gene expression [4-6], modulation of the membrane receptors functionality $[7,8]$ and free radicals' generation [9-11]. In 2002, the IARC classified ELF-EMFs as a "possible human carcinogen" and the decision IARC was supported by the WHO in 2007 [12]. However, exposure to $50 \mathrm{~Hz}$ electric and magnetic fields is hazardous to

Corresponding author: alaa.khalil@pua.edu.eg

DOI: 10.21608/ajnsa.2019.4238.1098

(C) Scientific Information, Documentation and Publishing Office (SIDPO)-EAEA 
human health. In view of the epidemiological studies, the possibility remains that intense and prolonged exposures to electromagnetic fields may increase the risk of leukemia in children. [13].

There are other studies that investigated the possible hazardous effects of ELF -EMFs on cytosolic calcium concentration which plays substantial role as a ubiquitous second messenger in several key biochemical pathways and is thought to be an important mechanism for controlling and synchronizing physiological responses [14]. Effects of electromagnetic radiation exposure on bone mineral density and oxidative stress index in electrical workers were studied $[15,16]$. The study indicated a significant decrease in BMD, serum ALP, $\mathrm{Ca}, \mathrm{P}$ and antioxidant enzyme levels. On the other hand, the high energy photons show clearly effects and interpreted modes of interactions with biological systems and specific standards are defined for exposure to such types of radiations. In this regard, changes were monitored in calcium concentration, collagen concentration and some biophysical properties such as (stress, tensile strain, bending moment and hysteresis loop) of bone after exposures to different doses of X-ray from (6 $\mathrm{MeV}$ ) linear accelerator [17]. Bone is a highly specialized supporting framework of the body, and thus, it was chosen to be a biomarker for the evaluation of the associating hazardous effect. This was achieved through measurements of bone biomechanical and biochemical parameters relatively to exposure of standard dose of $1 \mathrm{rad} 6$ $\mathrm{MeV}$ photons.

\section{Material and Methods}

In the present work, 100 male albino rats were used, each of an average weight $170 \pm 15 \mathrm{~g}$, and they were divided into subgroups ten rats each group $A, E, E_{1}, E_{2}, E_{3}, E_{4}, D_{1}, D_{2}, D_{3}$, and $D_{4}$. Animals of all groups were housed in normal environmental conditions and the temperature inside the lab varied between (23-25) ${ }^{\circ} \mathrm{C}$. Lighting condition is natural light from large windows during the day and complete darkness during the night. Animals of group A were used as unexposed group (control group) and did not receive any treatment. Animals in groups $\mathrm{E}_{1}, \mathrm{E}_{2}, \mathrm{E}_{3}$ and $E_{4}$ were exposed to an electric field $(4 \mathrm{kV} / \mathrm{m}$ $50 \mathrm{~Hz}$ ) for a period of $1,2,3$ and 4 weeks respectively for $8 \mathrm{~h} /$ day. At the end of the exposure period for each group, they were immediately sacrificed. Animals of $\mathrm{D}_{1}, \mathrm{D}_{2}, \mathrm{D}_{3}$, and $\mathrm{D}_{4}$ groups were also exposed to $(4 \mathrm{kV} / \mathrm{m}-50 \mathrm{~Hz})$ for periods of $1,2,3$, and 4 weeks for $8 \mathrm{~h} /$ day but remained 45 days post each exposure periods before sacrificed. Animals of group E were exposed to high energy photons $(6 \mathrm{MeV})$ of a dose (1rad) emitted from linear accelerator (LINAC) at Faculty of Medicine, Alexandria University. The animals were placed where the LINAC's output measurements are made to ensure the correct output factor for energy $6 \mathrm{MeV}$. It is measured collimator and couch angles adjusted to be $0^{0}$ and (source to surface distance) SSD $=100 \mathrm{~cm}$ and were immediately sacrificed after exposure. The exposure cage consisted of Perspex chamber, with an exposure volume of dimension 100x30x35 $\mathrm{cm}^{3}$ located between two parallel aluminum plates, which extended vertically along two parallel sides of the exposure cage. In order to prevent any animal shock from direct contacts with the electrodes, the aluminum plates were covered by front fixed Perspex plates of a similar measure. It has been previously reported that the Perspex material had a negligible effect on the field uniformly [18]. The two Al electrodes were connected to a step up transformer with an out put voltage of $4 \pm 0.2 \mathrm{kV}$ when connected to the main supply. The electric field inside the chamber was measured through the use of field meter and was found to be uniform and reads $4 \mathrm{kV} / \mathrm{m}$.

Femur bone samples are dissected, free cleaned of soft tissues and then biophysical analysis was conducted. The samples were soaked into saline solution and then frozen at $-20^{\circ} \mathrm{C}$ in an airtight plastic bag until the others testing. Before testing, the frozen bone specimens in the saline solution were left at room temperature for at least 3 hours [19-20]. After drying the samples, the mechanical and chemical properties were measured. For the mechanical testing, the Mark-10 ESM 300 motorized bending tester was used. Each bone specimen diameter was measured at three levels by micrometer then, an average radius was considered. For three points bending whole femur was placed on the stand Copper (stainless-resistant and loading bar (stainless copper plate with a radius of $2 \mathrm{~mm}$ ) was oriented perpendicular to the longitudinal axis of the bone and positioned at the midpoint femur [21].

The load was applied at the mid-diaphysis in femur with loading speed of $10 \mathrm{~mm} / \mathrm{min}$. Loaddeformation curves were plotted for all groups in bending test and structural properties (stiffness, 
maximum Load $\left(\mathrm{F}_{\max }\right)$, maximum displacement $(\Delta$ $\max )$ ) were obtained from the curves. Moreover, stress - strain curves are plotted and material properties (modulus of elasticity (E), ultimate strain $\varepsilon(\mathrm{U})$, ultimate stress $\sigma(\mathrm{U})$ and toughness (T)) were determined from the curves.

On the other hand, bone specimens were extracted for calcium assays using the method adapted by Burr D B. [22]. Moreover, the bone collagen concentration was performed by calculating the total amount of hydroxyproline in each sample, assuming 300 hydroxyproline residues per collagen molecule and a molecular weight of collagen of $300,000 \mathrm{D}$, and was normalized to either tissue dry weight or total protein weight [23]. The measurements of serum ALP were carried out by means of Abbott Architect Plus-C 16000 device with photometry kinetic method [24].

SPSS for Windows statistical package program (SPSS Inc., ver. 21) was used for statistical analysis. All the data were presented as mean \pm standard deviation (SD). Significant differences between groups were obtained using One-way analysis of variance (ANOVA). Post hoc Tukey test (least significant differences test) was used to determine the differences between specific means when the one-way ANOVA revealed a significant difference. A " $p$ " of $<0.05$ is considered statistically significant and used for all the comparisons.

\section{Results and Discussion}

There are many studies on the effects of exposure to ELF electromagnetic fields and its hazardous effects, but with contradictory and insufficient information to predict and speculate its modes of interactions with biological tissues. On the other hand, the high energy photons show clearly effects and interpreted modes of interactions with biological systems and specific standards are defined for exposure to such types of radiations. Therefore, this research aims at evaluating the fore- mentioned biological effects in bone samples exposed to $4 \mathrm{kV} / \mathrm{m}-50 \mathrm{~Hz}$ relatively to biological damages resulted from exposure to standard dose (1rad) of high energy photons $6 \mathrm{MeV}$. The loading displacement curves are normalized by shafts area and stress- strain curves which are performed. All curves indicate the same normal bending characteristics of linear strain response to applied stress until ultimate point and followed by nonlinear portion till the breaking point. The stress is taken at specific value $5 \mathrm{MN} / \mathrm{m}^{2}$ to compare corresponding average strain values for all assigned groups. Strain values depicted a significant decrease for the exposed and delayed post exposed groups than control group A. Also, femur structural and material properties are calculated for all samples; their average values with standard deviation are taken and tabulated in Tables (1 and 2). The results indicated a remarkable increase in femur stiffness and its modulus of elasticity for exposed in comparison to unexposed one and trended to values of group A for delayed post exposed groups. On contrary, the maximum displacement and ultimate strain values depicted a significant shift to lower values for exposed and delayed post exposed groups in comparison to unexposed one. The total strain energy, stored at the point of failure, is known as the toughness of bone sample, which represents the amount of energy needed to cause a fracture. Its intrinsic and extrinsic values for the exposed and delayed post exposed values did not show a remarkable difference compared to the unexposed one. In most of other parameters (maximum applied force, ultimate stress and bending moment) there are slight deviations in comparison to the unexposed group.

Bone matrix is a two-phase system in which the mineral phase provides the stiffness and the collagen fibers provide the ductility and ability to absorb energy (i.e., the toughness). Alterations of collagen properties can therefore affect the mechanical properties of bone and increase fracture susceptibility [25, 26]. Several studies suggest that part of the large variation in bone strength may be related not only in the mineral contents, but also differences in the quality of the collagenous matrix, including the nature and extent of its posttranslational modification [27]. An ELF EMFs can induce differentiation of cartilage cells and alter alkaline phosphatase activity in rat osteoblastic cells [29].

The average values for all measured biochemical parameters are calculated and tabulated in Table (3). The data of calcium content indicates a significant deterioration for the exposed group and irregularity differences for the delayed post exposure groups except for group $\mathrm{D}_{1}$ did not show any significant difference to group $\mathrm{A}$. The phosphorus content shows a similar deterioration and a significant decrease for the examined groups.

Arab J. Nucl. Sci. \& Applic. Vol. 52, No. 4 (2019) 
Table (1): Average structural properties for all femur samples from each group (mean values \pm S.D)

\begin{tabular}{|c|c|c|c|c|c|}
\hline Group & $\begin{array}{c}\text { Ultimate } \\
\text { strain } \boldsymbol{\varepsilon} \\
(\mathbf{U}) \pm \text { S.D }\end{array}$ & $\begin{array}{c}\text { Average Toughness } \\
\text { values (MPa) } \pm \text { S.D }\end{array}$ & $\begin{array}{c}\text { Average M } \\
\text { (bending moment) } \\
\text { values (N.m) }\end{array}$ & $\begin{array}{c}\text { Elastic } \\
\text { Modulus E } \\
(\mathbf{M P a}) \pm \text { S.D }\end{array}$ & $\begin{array}{c}\text { Ultimate } \\
\text { stress } \boldsymbol{\sigma}(\mathbf{u}) \\
(\mathbf{M P a}) \pm \text { S.D }\end{array}$ \\
\hline $\mathrm{A}$ & $0.046 \pm 0.018$ & $0.34 \pm 0.036$ & $0.36 \pm 0.047$ & $243.03 \pm 16.09$ & $113 \pm 2.6$ \\
\hline $\mathrm{E}_{1}$ & $0.0403 \pm 0.018$ & $0.51 \pm 0.070$ & $0.24 \pm 0.039$ & $270.45 \pm 10.12$ & $126 \pm 2.0$ \\
\hline $\mathrm{E}_{2}$ & $0.031 \pm 0.012$ & $0.33 \pm 0.112$ & $0.33 \pm 0.058$ & $365.93 \pm 84.73$ & $144 \pm 1.4$ \\
\hline $\mathrm{E}_{3}$ & $0.0405 \pm 0.013$ & $0.43 \pm 0.031$ & $0.30 \pm 0.008$ & $315.05 \pm 10.68$ & $139 \pm 1.5$ \\
\hline $\mathrm{E}_{4}$ & $0.039 \pm 0.14$ & $0.37 \pm 0.055$ & $0.39 \pm 0.096$ & $358.64 \pm 38.28$ & $152 \pm 3.0$ \\
\hline $\mathrm{D}_{1}$ & $0.033 \pm 0.003$ & $0.18 \pm 0.045$ & $0.38 \pm 0.021$ & $222.13 \pm 37.53$ & $83.6 \pm 3.5$ \\
\hline $\mathrm{D}_{2}$ & $0.064 \pm 0.0305$ & $0.44 \pm 0.048$ & $0.45 \pm 0.104$ & $262.97 \pm 30.58$ & $126 \pm 3.6$ \\
\hline $\mathrm{D}_{3}$ & $0.052 \pm 0.012$ & $0.30 \pm 0.038$ & $0.45 \pm 0.025$ & $234.80 \pm 51.54$ & $108 \pm 1.0$ \\
\hline $\mathrm{D}_{4}$ & $0.072 \pm 0.009$ & $0.55 \pm 0.062$ & $0.51 \pm 0.040$ & $226.81 \pm 10.04$ & $157 \pm 9.3$ \\
\hline $\mathrm{E}$ & $0.0456 \pm 0.011$ & $0.31 \pm 0.086$ & $0.38 \pm 0.086$ & $180.71 \pm 72.35$ & $105 \pm 1.4$ \\
\hline
\end{tabular}

Table (2): Average material properties for all femur samples from each group (mean values \pm S.D)

\begin{tabular}{|c|c|c|c|c|}
\hline Group & $\begin{array}{c}\text { Stiffness } \\
(\mathbf{k N} / \mathbf{m m}) \pm \\
\text { S.D. }\end{array}$ & $\begin{array}{c}\text { Displacement at } \\
\text { Max. Load } \\
\Delta \max (\mathbf{m m}) \pm \text { S.D. }\end{array}$ & $\begin{array}{c}\text { Max. Load } \\
\text { F (N) } \\
\pm \text { S.D. }\end{array}$ & $\begin{array}{c}\text { Energy to max. } \\
\text { force } \\
(\mathrm{mJ}) \pm \text { S.D. }\end{array}$ \\
\hline $\mathrm{A}$ & $9.8 \pm 0.6$ & $0.001 \pm 0.0002$ & $99.75 \pm 13.14$ & $0.046 \pm 0.018$ \\
\hline $\mathrm{E}_{1}$ & $13.7 \pm 0.32$ & $0.0023 \pm 0.0002$ & $66.93 \pm 10.85$ & $0.0403 \pm 0.018$ \\
\hline $\mathrm{E}_{2}$ & $15.7 \pm 0.34$ & $0.0019 \pm 0.0003$ & $90.89 \pm 16.23$ & $0.031 \pm 0.012$ \\
\hline $\mathrm{E}_{3}$ & $12.7 \pm 0.24$ & $0.0011 \pm 0.0002$ & $84.37 \pm 2.16$ & $0.0405 \pm 0.013$ \\
\hline $\mathrm{E}_{4}$ & $17.8 \pm 0.27$ & $0.0015 \pm 0.0002$ & $110 \pm 26.52$ & $0.039 \pm 0.14$ \\
\hline $\mathrm{D}_{1}$ & $19.3 \pm 0.87$ & $0.0018 \pm 0.0003$ & $105.98 \pm 5.86$ & $0.033 \pm 0.003$ \\
\hline $\mathrm{D}_{2}$ & $18.3 \pm 0.15$ & $0.0019 \pm 0.0002$ & $126.07 \pm 28.65$ & $0.064 \pm 0.0305$ \\
\hline $\mathrm{D}_{3}$ & $18.4 \pm 0.24$ & $0.0010 \pm 0.00026$ & $125.45 \pm 7.04$ & $0.052 \pm 0.012$ \\
\hline $\mathrm{D}_{4}$ & $14.0 \pm 0.63$ & $0.0023 \pm 0.00046$ & $141.51 \pm 11.11$ & $0.072 \pm 0.009$ \\
\hline $\mathrm{E}$ & $12.8 \pm 0.6$ & $0.002 \pm 0.0003$ & $106.72 \pm 15.28$ & $0.0456 \pm 0.011$ \\
\hline
\end{tabular}

Table (3): Average biochemical parameters for all femur samples from each group(mean values \pm S.D)

\begin{tabular}{|c|c|c|c|c|}
\hline Group & $\begin{array}{c}\text { Average calcium } \\
\text { conc. }(\mathrm{mg} / \mathrm{dl}) . \\
\pm \text { S.D. }\end{array}$ & $\begin{array}{c}\text { Average } \\
\text { phosphorus } \\
\text { conc. (mg/dl). } \\
\pm \text { S.D }\end{array}$ & $\begin{array}{c}\text { Average collagen } \\
\text { conc. } \\
\text { (mg/100mg)\% } \\
\pm \text { S.D. }\end{array}$ & $\begin{array}{c}\text { Average ALP } \\
\text { conc. }(\mathrm{mg} / \mathrm{dl}) \text {. } \\
\pm \text { S.D. }\end{array}$ \\
\hline $\mathrm{A}$ & $4.38 \pm 0.19$ & $2.78 \pm 0.34$ & $214 \pm 21.29$ & $65.6 \pm 7.23$ \\
\hline $\mathrm{E}_{1}$ & $3.74 \pm 0.26$ & $2.02 \pm 0.35$ & $138 \pm 2.79$ & $74.7 \pm 4.49$ \\
\hline $\mathrm{E}_{2}$ & $2.96 \pm 0.09$ & $2.13 \pm 0.04$ & $142 \pm 4.83$ & $83.0 \pm 5.54$ \\
\hline$E_{3}$ & $2.50 \pm 0.11$ & $1.70 \pm 0.31$ & $128 \pm 14.75$ & $76.8 \pm 8.43$ \\
\hline $\mathrm{E}_{4}$ & $2.30 \pm 0.11$ & $2.06 \pm 0.98$ & $114 \pm 14.23$ & $62.5 \pm 14.02$ \\
\hline $\mathrm{D}_{1}$ & $4.10 \pm 0.21$ & $2.34 \pm 0.56$ & $169 \pm 5.53$ & $39.9 \pm 3.76$ \\
\hline $\mathrm{D}_{2}$ & $2.70 \pm 0.21$ & $1.44 \pm 0.19$ & $161 \pm 8.43$ & $89.6 \pm 9.03$ \\
\hline $\mathrm{D}_{3}$ & $1.89 \pm 0.14$ & $2.13 \pm 0.68$ & $141 \pm 21.25$ & $78.0 \pm 6.32$ \\
\hline $\mathrm{D}_{4}$ & $3.98 \pm 0.29$ & $1.85 \pm 1.09$ & $209 \pm 7.73$ & $51.1 \pm 4.84$ \\
\hline $\mathrm{E}$ & $1.70 \pm 0.21$ & $0.99 \pm 0.22$ & $106 \pm 1.58$ & $63.0 \pm 5.08$ \\
\hline
\end{tabular}


Table (4): Represents relative fraction of damage values of femur samples after application of three points bending moment

\begin{tabular}{|c|c|c|c|c|c|c|c|c|c|}
\hline & Stiffness & $\Delta(\mathbf{m a x})$ & $\mathbf{F}(\mathbf{m a x})$ & Energy & $\begin{array}{c}\text { Modulus of } \\
\text { elasticity }\end{array}$ & $\boldsymbol{\varepsilon}(\mathbf{U})$ & $\boldsymbol{\sigma}(\mathbf{U})$ & Toughness & $\begin{array}{c}\text { Bending } \\
\text { moment }\end{array}$ \\
\hline E1 & 1.322 & 0.798 & 1.594 & 1.131 & 0.668 & 1.594 & 0.832 & 0.605 & 1.594 \\
\hline E2 & 0.818 & 0.981 & 1.174 & 1.474 & 0.494 & 1.174 & 0.729 & 0.935 & 1.174 \\
\hline E3 & 1.021 & 1.706 & 1.264 & 1.126 & 0.574 & 1.265 & 0.755 & 0.71 & 1.265 \\
\hline E4 & 0.72 & 1.198 & 0.97 & 1.171 & 0.504 & 0.97 & 0.692 & 0.84 & 0.97 \\
\hline D1 & 0.663 & 1.01 & 1.007 & 1.374 & 0.814 & 1.006 & 1.259 & 1.73 & 1.007 \\
\hline D2 & 0.701 & 0.981 & 0.846 & 0.706 & 0.687 & 0.846 & 0.834 & 0.693 & 0.846 \\
\hline D3 & 0.693 & 1.718 & 0.851 & 0.883 & 0.77 & 0.851 & 0.973 & 1.034 & 0.851 \\
\hline D4 & 0.913 & 0.807 & 0.741 & 0.634 & 0.797 & 0.754 & 0.669 & 0.465 & 0.754 \\
\hline
\end{tabular}

Table (5): represents relative fraction of damage values of femur samples after biochemical analysis

\begin{tabular}{|c|c|c|c|c|}
\hline & Calcium & Phosphorus & collagen & ALP \\
\hline E1 & 0.788 & 0.792 & 0.64 & 0.693 \\
\hline E2 & 1.162 & 0.841 & 0.855 & 0.951 \\
\hline E3 & 0.828 & 0.763 & 0.725 & 1.101 \\
\hline E4 & 0.858 & 0.79 & 0.759 & 1.763 \\
\hline D1 & 0.607 & 0.511 & 0.688 & 0.97 \\
\hline D2 & 0.499 & 0.342 & 0.539 & 1.55 \\
\hline D3 & 0.695 & 0.628 & 0.914 & 1.239 \\
\hline D4 & 0.733 & 0.984 & 0.875 & 1.147 \\
\hline
\end{tabular}

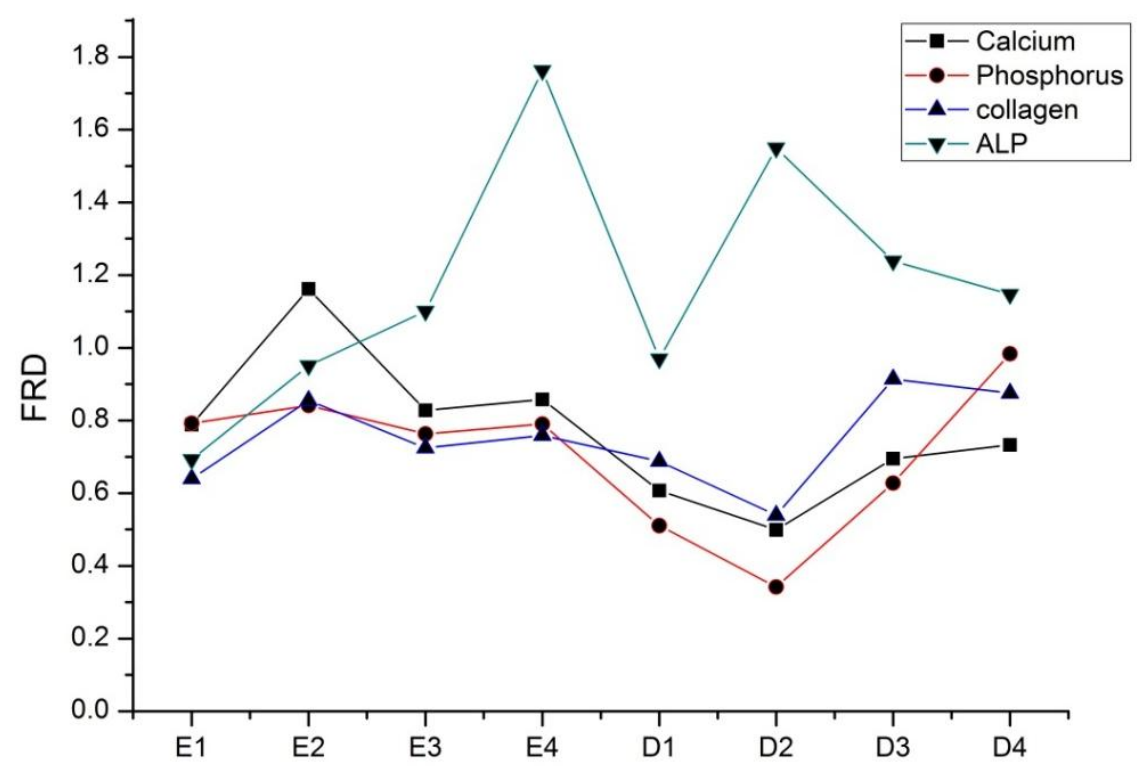

Fig. (1): variations of biochemical parameters for all femur samples 
A remarkable shift to lower values in the collagen concentration of bone samples was observed and the shift is increased as much exposure time increased, except group $\mathrm{D}_{4}$ did not follow the same manner and retained collagen as the unexposed group A. The direct effect of exposure is detected clearly in the increase of ALP enzyme in blood for the exposed groups $\mathrm{E}_{1}, \mathrm{E}_{2}$, and $\mathrm{E}_{3}$. Relative fraction of damage RFD was calculated for all the studied parameters of the exposed groups and delayed by 45 days post exposure groups relative to high energy photons (1rad) and listed in Tables (4 and 5). The RFD is obtained by dividing the changes of all examined parameters over changes due to high energy photons relatively to unexposed group A. The data revealed significant effects of 4 $\mathrm{kV} / \mathrm{m}-50 \mathrm{~Hz}$ exposure not less than $6 \mathrm{MeV}-1 \mathrm{rad}$ exposure for intrinsic and extrinsic interbiomechanical parameters. Particularly, the maximum load and bending moment values showed the highest RFD ration than other parameters. It is worthy to mention here that the effect of the changes in the exposure periods and/or delaying factor did not show a significant diversity or specific trends in RFD among all groups. The measured calcium, phosphorus and collagen concentrations indicated low RFD compared to other measured biomechanical and bioelectrical parameters as listed in Table (5). The former findings are attributed to the highly remarkable effects of exposure to high energy photons in bone minerals and collagen contents. The only exception of serum ALP level indicated a higher deterioration compared to other biochemical parameters due to the exposure of electric fields as shown in Fig. (1).

\section{Conclusion}

The results speculated the exposure to such fields reduces the bone quality by affecting mineralization and collagen integrity. The results obtained from the delayed by 45-days post exposure effect did not show amendment in bone biophysical characteristics, which means that permanent effects and chronic damage of bone tissues may be resulted. Relative fraction of damage of biophysical bone characteristics illustrate that the effect of the exposure to ELF EMF has no less effect than exposure to ionizing radiation and should not be underestimated. New recommendations for exposure to such fields should be demonstrated and further evaluations should be considered to highlight the possible health hazardous effects.

\section{References}

1. Lisi, M. Ledda, F. De Carlo et al., "Calcium ion cyclotron resonance (ICR) transfers information to living systems: effects on human epithelial cell differentiation," Electromagnetic Biology and Medicine, vol. 27, no. 3, 2008; pp. 230-240.

2. G. Vianale, M. Reale, P. Amerio, M. Stefanachi, S. Di Luzio, and R. Muraro, "Extremely low frequency electromagnetic field enhances human keratinocyte cell growth and decreases proinflammatory chemokine production," British Journal of Dermatology, vol. 158, no. 6, 2008; pp. 1189-1196.

3. Berg, H., Electrostimulation of cell metabolism by low frequency electric and electromagnetic fields, Bioelectrochem. Bioenerg., 1993, 31, 1-25.

4. R. Piacentini, C. Ripoli, D. Mezzogori, G.B. Azzena, and C. Grassi, "Extremely low-freauency electromagnetic fields promote in vitro neurogenesis via upregulation of Cav1- channel activity," Journal of Cellular Physiology, vol. 215, no. 1, 2008; pp. 129-139.

5. Liu X, Zhao L, Yu D, Ma S, Liu X. 2013, Effects of extremely low frequency electromagnetic field on the health of workers in automotive industry Electromagn Biol Med., 32 (4):551-9.

6. R. Goodman, A. Lin-Ye, M.S. Geddis et al., "Extremely low frequency electromagnetic fields activate the ERK cascade, increase hsp70 protein levels and promote regeneration in Planaria," International Journal of Radiation Biology, vol. 85, no. 10, 2009; pp. 851-859.

7. X.Q. Ke, W.J. Sun, D.Q. Lu, Y.T. Fu, and H. Chiang, "50 Hz magnetic field induces EGFreceptor clustering and activates RAS," International Journal of Radiation Biology, vol. 84, no. 5, 2008, pp. 413-420.

8. M. de Mattei, K. Varani, F.F. Masieri et al., "Adenosine analogs and electromagnetic fields inhibit prostaglandin E2 release in bovine synovial fibroblasts," Osteoarthritis and Cartilage, vol. 17, no. 2, 2009, pp. 252-262.

9. C. Morabito, F. Rovetta, M. Bizzarri, G. Mazzoleni, G. Fano, and M.A. Mariggio, "Modulation of redox status and calcium handling by extremely low frequency electromagnetic fields in $\mathrm{C} 2 \mathrm{C} 12$ muscle cells: a real-time, single-cell approach," Free Radical Biology and Medicine, vol. 48, no. 4, 2010; pp. 579-589.

10. F.I. Wolf, A. Torsello, B. Tedesco et al., "50 Hz extremely low frequency electromagnetic fields 
enhance cell proliferation and DNA damage: possible involvement of a redox mechanism," Biochimica et Biophysica Acta, vol. 1743, no. 1-2, 2005; pp. 120-129.

11. S. Di Loreto, S. Falone, V. Caracciolo et al., "Fifty hertz extremely low-frequency magnetic field exposure elicits redox and trophic response in ratcortical neurons," Journal of Cellular Physiology, vol. 219, no. 2, 2009; pp. 334-343.

12. WHO (World Health Organization). Extremely Low Frequency Fields, Environmental Health Criteria Monograph No. 238. Retrieved from http://www.who.int/entity/pehemf/publications/Complet_DEC_2007.pdf.

13. ARPANSA (Australian Radiation Protection and Nuclear Safety Agency). (2011a). Electricity and Health, Canberra, ACT: Commonwealth of Australia.

Retrieved:http://www.arpansa.gov.au/radiationprot ection/factsheets/is_electricity.

14. McCreary, C.R., Dixon, S.J., Fraher, L.J., Carson, J.J. and Prato, F.S. Real-time measurement of cytosolic free calcium concentration in Jurkat cells during ELF magnetic field exposure and evaluation of the role of cell cycle. Bioelectromagnetics. 2006; 27(5):354-364.

15. Kunt H, Şentürk İ, Gönül Y, Korkmaz M, Ahsen A, Hazman Ö, Bal A, Genç A, Songur A. 2016, Effects of electromagnetic radiation exposure on bone mineral density, thyroid, and oxidative stress index in electrical workers.", Onco Targets and Therapy, 9, 745-754.

16. Mai. I. El-kaliuoby et al. Monitoring of relative changes in rats' tibia bone characteristics after exposure to $4 \mathrm{kV} / \mathrm{m}-50 \mathrm{~Hz}$ Electric fields, international journal of current research, 2017, 9 (12), 62026-62031.

17. ARD El-Karim, A.A., AL-khateeb,A. , and AlKhouli, S. Study The Effect of Medium XRAY Doses from Linear Accelerator (6 MV) On Some Biophysical Properties of Rat Bone. Master Thesis.2015;1-107

18. Kaune W.T.,: A prototype system for exposing small laboratory animals to $60 \mathrm{~Hz}$ vertical electric fields: electric measurements. In biological effects of extremely low frequency electromagnetic fields, 1979, PP: 225, proceeding of the eighteenth annual Hanford life science symposium at Richland Washington.

19. Abd El-Karim, A.A., AL-khateeb, A., and AlKhouli, S. Study the Effect of Medium X-RAY Doses from Linear Accelerator (6 MV) On Some Biophysical Properties of Rat Bone. Master Thesis.2015; 1-107.

20. Jast, J. Investigation of Ultrastructural and Mechanical Properties of Rat Cortical Bone Using Micro-Ct, Three- Point Bending Testing, and the Reference Point Indentation Technique. 2011,50.
21. An, Y.H., Draughn, R.A. (Eds.). Mechanical testing of bone and the bone-implant interface. CRC press. 1999; 1-642.

22. Burr D B., The contribution of the organic matrix to bone's material properties. 2002, Bone, 31:8-11.

23. Gonzalez-Riola J, Pamies JA, Hernandez ER, Revilla M, Seco C, Villa LF, Rico H. 1997, Influence of electromagnetic fields on bone mass and growth in developing rats: a morphometric, densitometric and histomorphometric study. Calcif Tissue Int., 60:533-7.

24. H. Kunt et al., The Assessment as Bone Mineral Density of Bone Damage in Radiology Workers Occupationally Exposed to Ionizing Radiation, 2013, Eur J Gen Med;10 (4): 214-218

25. Halil. K, Hayri .D, The Effects of Radiation on Bone Mineral Density of Radiology Workers Depending on The Device They Use. Eur J Gen Med 2011;8(4):318-322.

26. LaRue, S., Wrigley, R., Powers, B.A. Review Of The Effects Of Radiation Therapy On Bone. Veterinary Radiology. 1987; 28(1):17-22.

27. Agnieszka. S., Zygmunt K., Zbigniew W.," Preparation of hydroxyapatite from animal bones", Acta of Bioengineering and Biomechanics.2009, 11(4).

28. Oksztulska-Kolanek, E., Znorko, B., Michałowska, M., Pawlak, K. The Biomechanical Testing for the Assessment of Bone Quality in an Experimental Model of Chronic Kidney Disease' Nephron. 2016; 132:51-58. 